\title{
Prognostic value of pretreatment neutrophil-to-lymphocyte ratio in renal cell carcinoma: a systematic review and meta- analysis
}

Yuan Shao ${ }^{1 \dagger}$, Bo Wu ${ }^{2+}$, Wei Jia ${ }^{1}$, Zikuan Zhang ${ }^{1}$, Qian Chen ${ }^{1}$ and Dongwen Wang ${ }^{1,3^{*}}$ (1)

\begin{abstract}
Background: Numerous studies show that the pretreatment neutrophil-to-lymphocyte ratio (NLR) is associated with the prognosis of patients with RCC. However, their findings are inconsistent, urging us to explore the prognostic value of NLR in RCC patients.

Methods: This study was pre-registered in PROSPERO (CRD42020167131). Two reviewers independently performed a systematical search of PubMed, Web of Science, EMBASE, and Cochrane Library databases for prospective or retrospective cohort studies investigating the prognostic value of pretreatment NLR. Hazard ratios with 95\% confidence intervals for overall survival (OS), disease-free survival (DFS), progression-free survival (PFS), cancerspecific survival (CSS), and other useful clinicopathological features were extracted and analyzed with fixed or random-effect models by using Review Manager 5.3 and Stata 12.0 software. Heterogeneity was estimated on the basis of Cochran's $Q$ test and $P^{2}$ value. Sensitivity analyses and subgroup analyses were also performed to explore the potential sources of heterogeneity. Publication bias was assessed with funnel plots and precisely assessed by Egger's tests. The quality of the evidence was evaluated in accordance with the Grading of Recommendations Assessment, Development, and Evaluation (GRADE).
\end{abstract}

Results: Overall, 6461 RCC patients from 24 retrospective studies and 1 prospective study were included. In overall population, elevated pretreatment NLR was associated with poorer OS (pooled HR $=1.90,95 \% \mathrm{Cl}=1.56-2.30, p<$ $0.001 ; P^{2}=87 \%$ ), DFS/PFS (pooled HR=2.09, 95\% Cl: 1.49-2.94, $p<0.001 ; P^{2}=99 \%$ ), and CSS (pooled HR=2.31, 95\% Cl: $1.61-3.33, p<0.001 ; P=14 \%)$. Furthermore, this negative association was further confirmed in patients with nonmetastatic and metastatic RCC patients, respectively. We also investigated the predictive role of NLR in metastatic RCC patients treated with immune checkpoint inhibitors (ICIs). The results indicated that the level of NLR was significantly associated with OS (pooled HR=3.92, 95\% Cl: 2.00-7.69, $p<0.001 ; P^{2}=0 \%$ ) and PFS (pooled HR= $2.20,95 \%$ Cl: $95 \%$ Cl: $\left.1.61-3.01, p<0.001 ; P^{2}=20 \%\right)$.

\footnotetext{
*Correspondence: urology2007@126.com

${ }^{+}$Co-first authors: Yuan Shao and Bo Wu contributed equally to this work.

'Shanxi Medical University, Taiyuan 030001, Shanxi, People's Republic of China ${ }^{3}$ National Cancer Center/National Clinical Research Center for Cancer/Cancer Hospital \& Shenzhen Hospital, Chinese Academy of Medical Sciences and Peking Union Medical College, Shenzhen 518116, People's Republic of China Full list of author information is available at the end of the article
}

(c) The Author(s). 2020 Open Access This article is licensed under a Creative Commons Attribution 4.0 International License, which permits use, sharing, adaptation, distribution and reproduction in any medium or format, as long as you give appropriate credit to the original author(s) and the source, provide a link to the Creative Commons licence, and indicate if changes were made. The images or other third party material in this article are included in the article's Creative Commons licence, unless indicated otherwise in a credit line to the material. If material is not included in the article's Creative Commons licence and your intended use is not permitted by statutory regulation or exceeds the permitted use, you will need to obtain permission directly from the copyright holder. To view a copy of this licence, visit http://creativecommons.org/licenses/by/4.0/ The Creative Commons Public Domain Dedication waiver (http://creativecommons.org/publicdomain/zero/1.0/) applies to the data made available in this article, unless otherwise stated in a credit line to the data. 
(Continued from previous page)

Conclusions: This study demonstrated that elevated pretreatment NLR was significantly associated with poor prognosis of RCC patients. NLR could be helpful as a potential prognostic biomarker to guide clinical decisionmaking and select individualized treatment strategies for RCC patients.

Keywords: Inflammation, Neutrophil-lymphocyte ratio, Biomarker, Kidney neoplasms, Prognosis, Survival, Meta-analysis

\section{Background}

Renal cell carcinoma (RCC) is a common malignant cancer of the urinary system; its morbidity and mortality have been increasing in recent years $[1,2]$. When RCC is identified early by imaging conducted for other reasons serendipitously, long-term survival is generally excellent. When RCC is detected with symptoms, the prognosis is poor [3]. However, reliable biomarkers suitable for clinical application remain undiscovered worldwide, and presently except for imaging examination, no method is effective for the early diagnosis and prognosis of RCC. Therefore, in order to improve the prognosis of RCC patients and guide clinical decisionmaking, it is necessary to identify reliable pretreatment biomarker to diagnose, monitor, and manage this disease.

There is growing evidence indicating that immune response and systemic inflammation is the crucial component of human cancer development and progression [4-6]. Several studies have indicated that pretreatment neutrophil-to-lymphocyte ratio (NLR), as a systemic inflammatory biomarker, was associated with the prognosis of patients with malignancies; thus providing a new perspective for predicting the prognosis of cancer [7-9]. More recently, various studies evaluated the prognostic value of NLR in RCC patients, whereas their conclusions are controversial [10, 11]. In 2019, a meta-analysis reported that NLR is a predictor associated with prognosis in RCC patients. However, this study did not perform sensitivity analysis and subgroup analysis to explore the potential sources of heterogeneity and assess the publication bias [12]. Therefore, the aim of this systematic review and meta-analysis was to provide a systematical and comprehensive perspective clarifying the prognostic value of pretreatment NLR for both non-metastatic and metastatic RCC patients.

\section{Methods}

\section{Search strategy}

This study was pre-registered in PROSPERO (CRD42020167131) and conducted in accordance with the guidelines of the Preferred Reporting Items for Systematic Review and Meta-Analysis (PRISMA). A comprehensive online literature search was performed to select the potential studies on PubMed, Web of Science, EMBASE and Cochrane Library databases from inception to December 2019. The main terms used in our search strategy included the following: ("renal" or "kidney") and ("carcinoma" or "neoplasms" or "cancer" or "tumor") and ("NLR" or "neutrophil-lymphocyte ratio" or "neutrophil-to-lymphocyte ratio").

\section{Inclusion and exclusion criteria}

The enrolled studies should meet the following inclusion criteria: (1) prospective or retrospective cohort studies evaluating the association between the pretreatment NLR and overall survival (OS), disease-free survival (DFS), progression-free survival (PFS), cancer-specific survival (CSS) of the patients with RCC; (2) patients in these studies did not receive any treatment before obtaining samples; (3) NLR was collected within 30 days before treatment; and (4) the study directly provided hazard ratios (HRs) with 95\% confidence intervals (CIs) or had sufficient data to calculate these statistics. If the data in the studies were duplicated, only the data from the most recent study were used. The studies were excluded based on the following exclusion criteria: (1) studies without sufficient survival data for further analysis, (2) duplicated studies or publications, and (3) expert opinions, meeting abstracts, editorials, case reports, letters, reviews or meta-analysis.

\section{Date extraction}

For each eligible study, two separate authors independently extracted the following items: study characteristics (first author's name, recruitment region, year of publication, type of study, and sample size); patient information (gender, age, and race), pathological characteristics (TNM stage and histology subtype), disease setting (localized or metastatic), NLR cut-off values (the number and/or percentage of patients with high NLR versus those with low NLR), clinical features (treatment strategy, patient's survival outcome, and follow-up duration), OS, DFS, PFS, and CSS outcomes expressed as HRs (and 95\% CI) for RCC patients with high pretreatment NLR versus patients with low pretreatment NLR. In the case of disagreements between individual judgments, the consensus was achieved by discussion with the third investigator.

\section{Quality assessment}

The quality of each enrolled study was assessed using the Newcastle-Ottawa Scale (NOS), which consists of three factors: selection, comparability and exposure [13]. 
The highest score is 9 points and studies with scores 7 or more, 4-6, and lower than 4 were respectively considered to have a low, moderate, and high risk of bias. Any disagreement was resolved by discussion with the third reviewer.

\section{Statistical analysis}

Coprimary end-points of the present meta-analysis were OS, DFS, PFS, and CSS in all patients and in patients with nonmetastatic or metastatic RCC. When the included studies directly reported the survival analysis, the HRs and 95\% CIs were extracted and used to calculate pooled HRs; otherwise, the Engauge Digitizer software (version 4.1) was used to compute and estimate these data from the Kaplan-Meier survival curves [14, 15].

Cochran's Q test and $I^{2}$ statistic were used to assess the heterogeneity among the included studies. If significant heterogeneity existed $\left(I^{2}>50 \%\right.$ and/or $\left.P<0.10\right)$, the pooled HRs and 95\% CIs were calculated by a randomeffect model; otherwise, the fixed-effect model was performed $\left(I^{2}<50 \%\right.$ and/or $\left.P>0.10\right)$ [16]. Sensitivity analyses were conducted to assess the stability of the results by sequentially omitting a single study at a time. Subgroup analyses were conducted to explore the potential sources of heterogeneity. In addition, funnel plots and
Egger's tests were used to assess the risk of publication bias. Egger's test and the trim and fill method were performed with Stata 12.0 software (STATA Corporation, College Station, TX, USA). Other statistical analyses were conducted using Review Manager 5.3 software (Cochrane Collaboration, Copenhagen, Denmark). All $p$-values were two-sided, and a statistically significant difference was defined as $p<0.05$.

\section{Quality of evidence}

The quality of the evidence of the predictive value of pretreatment NLR for the prognosis in RCC patients was assessed according to the Grading of Recommendations Assessment, Development, and Evaluation (GRADE) [17].

\section{Results}

\section{Included literature}

Based on our search strategies, we identified 1039 potentially relevant studies. After removing duplicates, we viewed the titles and abstracts of the remaining 942 records. Subsequently, we assessed the full text for 76 articles. Finally, 25 studies were enrolled in the present meta-analysis $[10,11,18-40]$. The study selection process is presented as a flowchart in Fig. 1.

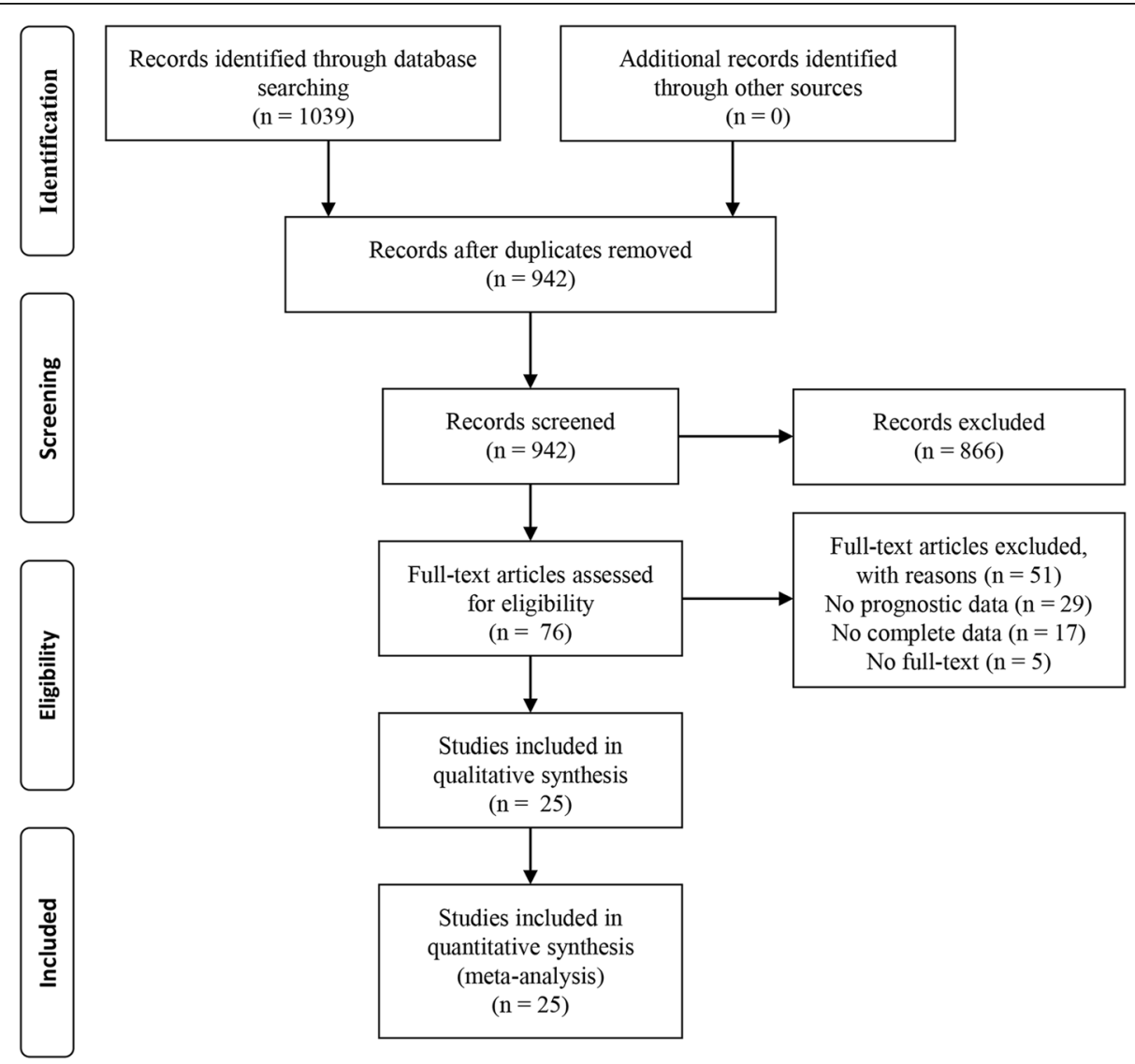

Fig. 1 Flowchart of the eligible studies in the current meta-analysis 


\section{Study characteristics}

Overall, 6461 patients with RCC were included. Table 1 showed the main characteristics of the 25 enrolled studies. For the study design, 24 were retrospective cohort studies and published between 2010 and 2019. Twelve studies reported localized/non-metastatic RCC, and 13 reported metastatic RCC. Among the 25 studies, OS was reported in 19 studies, DFS or PFS in 18 studies, and CSS in 4 studies. Histology type includes clear cell RCC, papillary RCC, non-clear cell RCC, and mixed type. Cutoff values of NLR ranged from 2.0 to 5.0. The HR and 95\% CI data were extracted from the multivariate Cox regression analysis in 25 studies and univariate analysis in two studies. The mean age ranged from 56.3 to 69 years and the mean follow-ups ranged from 7.6 to 107.6 months. The NOS scores ranged from 6 to 8, showing a moderate to high quality of the included studies (Table S1).

\section{NLR and OS in RCC}

Nineteen studies, comprising 5768 patients, evaluated the association of NLR with OS in RCC patients. Because of significant heterogeneity $\left(I^{2}=87 \%, p<0.001\right)$, a random-effect model was applied to investigate the prognostic role of NLR. The forest plot indicated that elevated pretreatment NLR was significantly associated with shorter OS in the overall population (pooled HR: 1.90, 95\% CI: 1.56-2.30, $p<0.001$, Fig. 2).

When we evaluated the relationship between pretreatment NLR and OS in nonmetastatic (localized) RCC, we investigated 8 studies, including 4113 patients, while the same relationship was possible in 11 studies including 1420 patients with metastatic RCC. Meta-analysis showed that elevated NLR was significantly associated with worse OS in patients with nonmetastatic and metastatic RCC (pooled HR $=1.78,95 \%$ CI: 1.24-2.56, $p<0.001$; pooled $\mathrm{HR}=2.04,95 \% \mathrm{CI}: 1.58-2.64, p<$ 0.001 , respectively). Of note, heterogeneity was still obvious in nonmetastatic $\left(I^{2}=85 \%, p<0.001\right)$ and metastatic populations $\left(I^{2}=72 \%, p<0.001\right)$ (Fig. 3 ).

To explore whether a single study affected heterogeneity and conclusions, we performed a sensitivity analysis by sequentially excluding each single study in turn. After removing Viers' study, heterogeneity among studies was reduced $\left(I^{2}=48 \%, p=0.07\right)$ in nonmetastatic RCC. Similarly, after removing Silagy's study, heterogeneity was reduced $\left(I^{2}=46 \%, p=0.05\right)$ in metastatic RCC. Overall, the results of sensitivity analyses did not affect the conclusions described above and validated the robustness of our findings.

\section{NLR and DFS, PFS in RCC}

When we investigated the association between NLR and DFS/PFS, 18 studies with 2735 patients were selected.
The forest plot revealed that a high pretreatment NLR resulted in worse DFS/PFS in overall population (pooled $\mathrm{HR}=2.09,95 \%$ CI: 1.49-2.94, $p<0.001 ; I^{2}=99 \%$; Fig. 2 ).

When we further evaluated the relationship between NLR and DFS in nonmetastatic RCC patients, we included 9 studies with 3602 patients. The forest plot revealed that elevated NLR showed a significant association with worse DFS (pooled HR $=1.45$, 95\% CI: 1.19-1.78, $p<0.001 ; I^{2}=$ 81\%; Fig. 3). As for the relationship between NLR and PFS in metastatic RCC patients, meta-analyses based on 9 studies indicated that high pretreatment NLR was significantly associated with poorer PFS (pooled $\mathrm{HR}=2.99,95 \%$ CI: $2.82-3.18, p<0.001 ; I^{2}=18 \%$; Fig. 3 ).

Consequently, sensitivity analyses were also performed in nonmetastatic RCC patients. The results showed that the omission of any one study, except Viers' study, did not significantly affect heterogeneity. However, heterogeneity was still relatively significant after the removal of Viers' study. Since different study features were involved, we further performed subgroup analyses to explore the source of heterogeneity (Table 2 ). In the subgroup analysis based on sample sizes, elevated pretreatment NLR was significantly associated with poorer DFS in both sample sizes $\geq 200$ (pooled HR $=1.57,95 \%$ CI: $1.09-2.26$, $p=0.02 ; I^{2}=69 \%$ ) and sample sizes $<200$ (pooled HR = 1.85, 95\% CI: $\left.1.17-2.92, p=0.008 ; I^{2}=60 \%\right)$. Moreover, histology type, mean age, cut-off value of NLR, treatment strategy, the mean follow-up months, and other study features did not affect the relationship between NLR and DFS in nonmetastatic RCC patients. Interestingly, when stratified by race of patients, heterogeneity was significantly reduced and results demonstrated that elevated NLR was significantly associated with pooer DFS in both Asian and Caucasian RCC patients (pooled $\mathrm{HR}=2.31 ; 95 \%$ CI: $1.70-3.14, p<0.001 ; I^{2}=0 \%$; pooled $\mathrm{HR}=1.21, \quad 95 \% \quad \mathrm{CI}: 1.08-1.36, \quad p=0.001 ; \quad I^{2}=0 \%$, respectively).

\section{NLR and CSS in RCC}

Four studies, comprising 2314 patients, provided data on the association of NLR with CSS. The forest plot indicated that higher pretreatment NLR was significantly associated with worse CSS (pooled $\mathrm{HR}=2.31,95 \% \mathrm{CI}$ : 1.61-3.33, $p<0.001, I^{2}=14 \%$; Fig. 2). Considering that the patients enrolled in these four studies were nonmetastatic RCC, we did not further investigated the association between NLR and CSS in metastatic RCC patients. Furthermore, a sensitivity analysis was performed to explore whether a single study affected heterogeneity and conclusions. After removing Zheng's study, heterogeneity among studies was markedly changed $\left(I^{2}=0 \%\right.$, $p=0.47)$ in nonmetastatic RCC. However, the pooled HR recalculated did not affect the conclusion described above, which validated the strength of our results. 


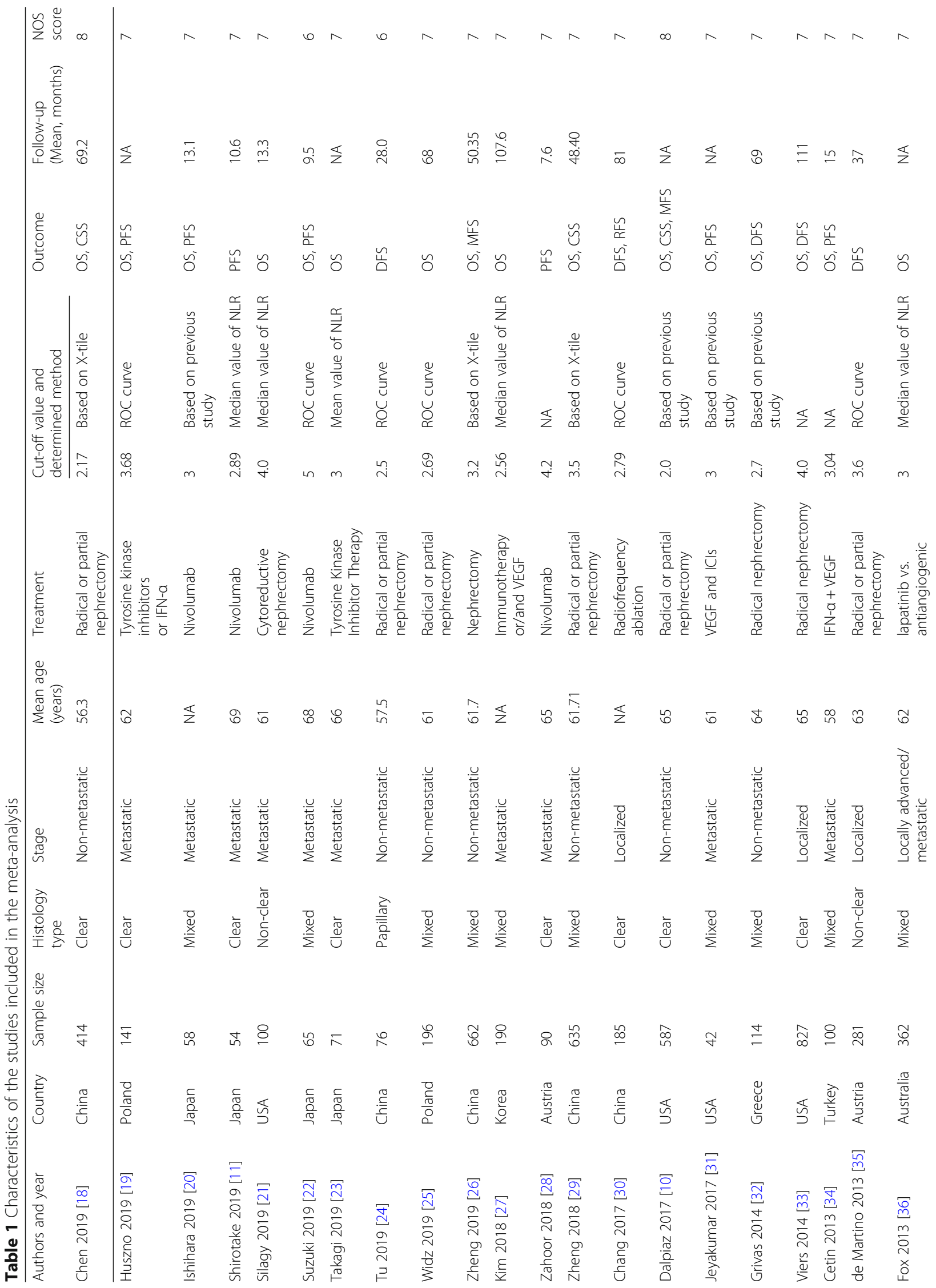


Shao et al. BMC Urology $\quad$ (2020) 20:90

Page 6 of 14

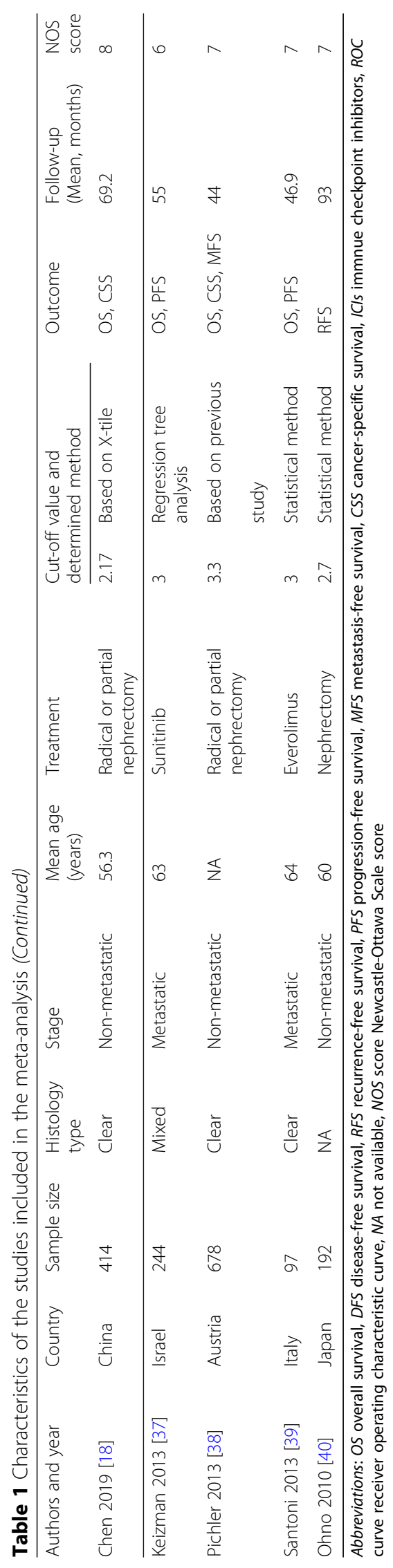




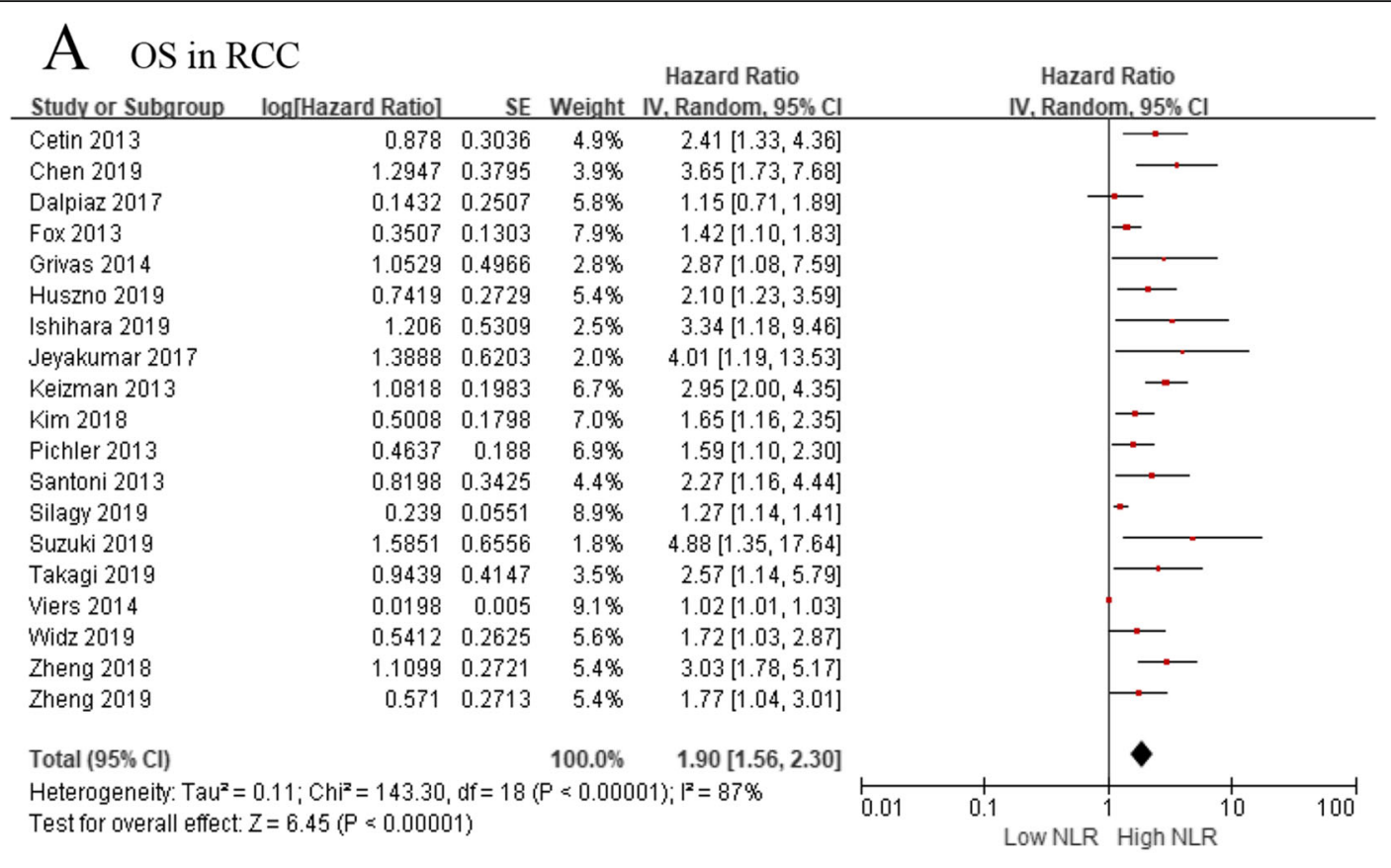

\section{B DFS/PFS in RCC}

\begin{tabular}{|c|c|c|c|c|c|c|c|c|}
\hline Study or Subgroup & log[Hazard Ratio] & SE & Weight & V. Random, $95 \% \mathrm{Cl}$ & \multicolumn{4}{|c|}{$\mathrm{om}, 95 \% \mathrm{Cl}$} \\
\hline Cetin 2013 & 1.107 & 0.0323 & $6.5 \%$ & $3.03[2.84,3.22]$ & & & - & \\
\hline Chang 2017 & 0.7715 & 0.2888 & $5.6 \%$ & $2.16[1.23,3.81]$ & & & & \\
\hline Dalpiaz 2017 & 0.7006 & 0.3419 & $5.2 \%$ & $2.01[1.03,3.94]$ & & & & \\
\hline Demartino 2013 & 0.157 & 0.07 & $6.5 \%$ & $1.17[1.02,1.34]$ & & & - & \\
\hline Griwas 2014 & 0.2062 & 0.1301 & $6.3 \%$ & $1.23[0.95,1.59]$ & & & + & \\
\hline Huszno 2019 & 1.0296 & 0.2142 & $6.0 \%$ & $2.80[1.84,4.26]$ & & & - & \\
\hline Ishihara 2019 & 0.4383 & 0.3311 & $5.3 \%$ & $1.55[0.81,2.97]$ & & & & \\
\hline Jeyakumar 2017 & 1.0774 & 0.3622 & $5.1 \%$ & $2.94[1.44,5.97]$ & & & & \\
\hline Keizman 2013 & 1.2556 & 0.194 & $6.1 \%$ & $3.51[2.40,5.13]$ & & & & \\
\hline Ohno 2010 & 0.7692 & 0.3452 & $5.2 \%$ & $2.16[1.10,4.25]$ & & & & \\
\hline Pichler 2013 & 0.3293 & 0.2509 & $5.8 \%$ & $1.39[0.85,2.27]$ & & & - & \\
\hline Santoni 2013 & 0.9783 & 0.3167 & $5.4 \%$ & $2.66[1.43,4.95]$ & & & $\rightarrow$ & \\
\hline Shirotake 2019 & 0.6366 & 0.4223 & $4.7 \%$ & $1.89[0.83,4.32]$ & & & & \\
\hline Suzuki 2019 & 1.5129 & 0.4364 & $4.6 \%$ & $4.54[1.93,10.68]$ & & & & \\
\hline Tu 2019 & 1.335 & 0.5881 & $3.7 \%$ & $3.80[1.20,12.03]$ & & & & \\
\hline Viers 2014 & 0.01 & 0.0051 & $6.6 \%$ & $1.01[1.00,1.02]$ & & & & \\
\hline Zahoor 2018 & 0.6206 & 0.2917 & $5.5 \%$ & $1.86[1.05,3.29]$ & & & & \\
\hline Zheng 2019 & 0.8372 & 0.2376 & $5.8 \%$ & $2.31[1.45,3.68]$ & & & & \\
\hline Total $(95 \% \mathrm{Cl})$ & & & $100.0 \%$ & $2.09[1.49,2.94]$ & & & & \\
\hline Heterogeneity: Tau & $46 ; \mathrm{Chi}^{2}=1258.6$ & $f=1$ & $(P<0.00$ & 01); $\left.\right|^{2}=99 \%$ & 0.01 & 0.1 & 10 & $100^{\circ}$ \\
\hline
\end{tabular}

\section{CSS in RCC}

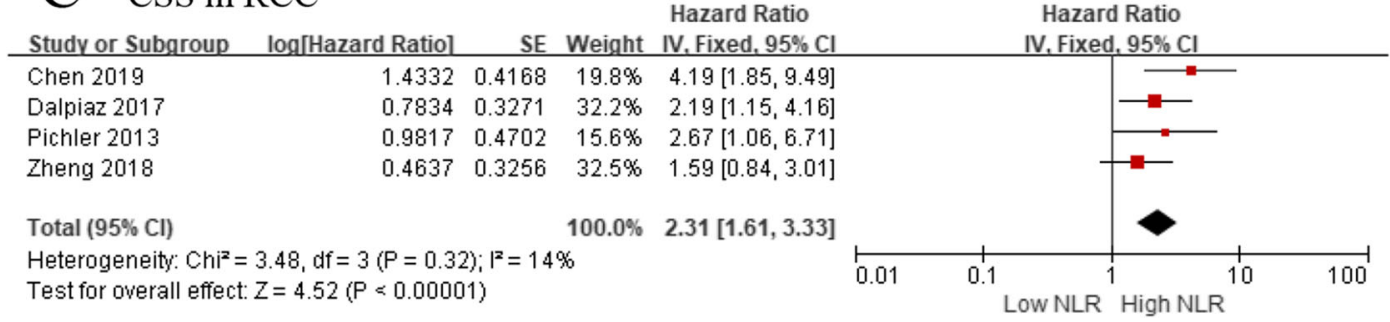

Fig. $\mathbf{2}$ a Effect of the NLR on overall survival, $\mathbf{b}$ effect of the NLR on disease-free survival/progression-free survival, $\mathbf{c}$ effect of the NLR on cancer-specific survival 


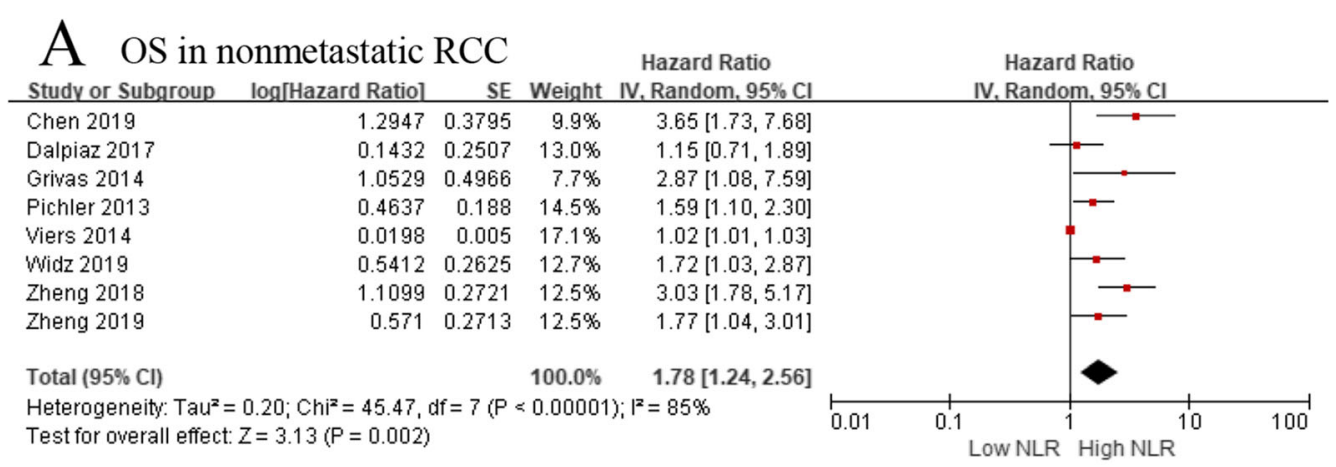

B OS in metastatic RCC

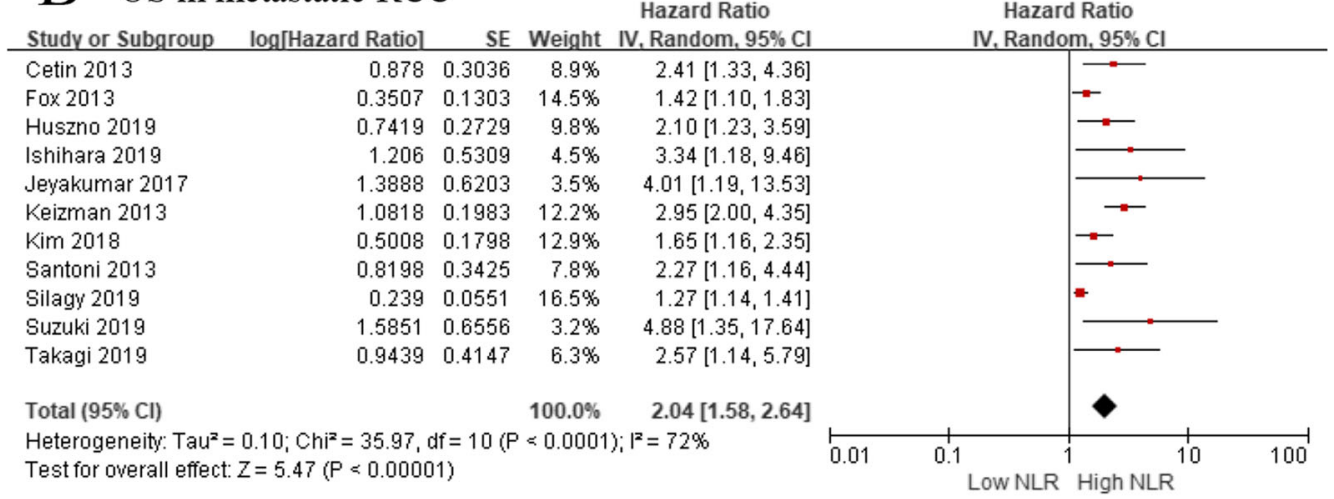

\section{DFS in nonmetastatic RCC}

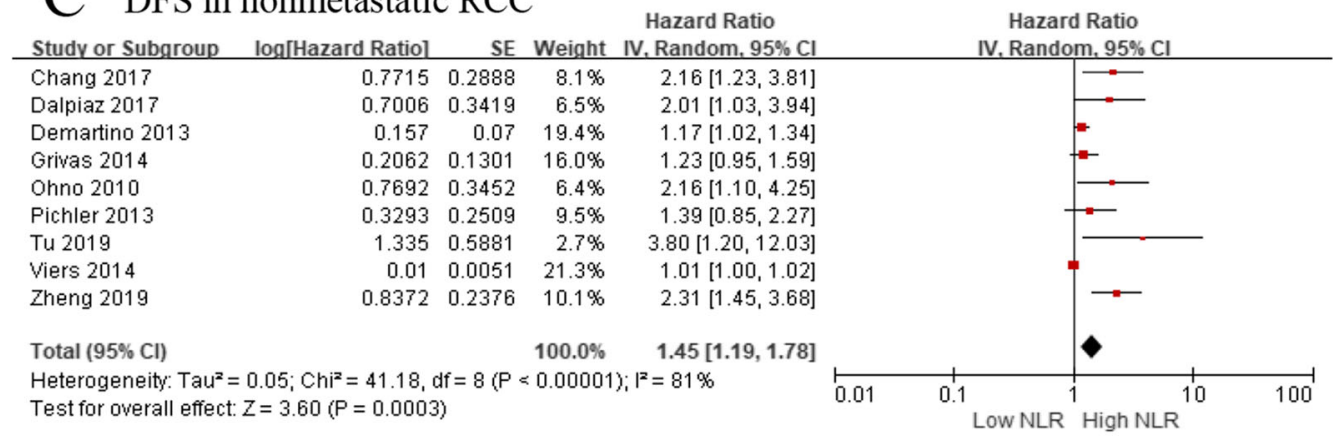

\section{PFS in metastatic RCC}

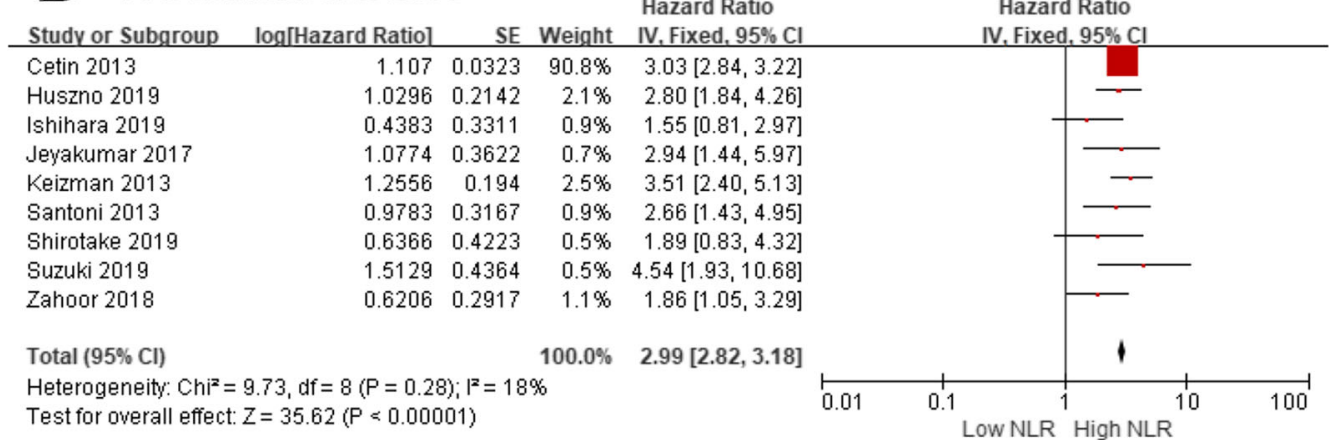

Fig. 3 a Effect of the NLR on OS in nonmetastatic RCC, $\mathbf{b}$ effect of the NLR on OS in metastatic RCC, $\mathbf{c}$ effect of the NLR on DFS in nonmetastatic RCC, $\mathbf{d}$ effect of the NLR on PFS in metastatic RCC 
Table 2 Subgroup analysis for DFS in non-metastatic RCC patients

\begin{tabular}{|c|c|c|c|c|c|c|}
\hline \multirow[t]{2}{*}{ Subgroup } & \multirow{2}{*}{$\begin{array}{l}\text { No. of } \\
\text { studies }\end{array}$} & \multirow{2}{*}{$\begin{array}{l}\text { No. of } \\
\text { patients }\end{array}$} & \multirow[t]{2}{*}{$\mathrm{HR}(95 \% \mathrm{Cl})$} & \multirow[t]{2}{*}{$P$ value } & \multicolumn{2}{|c|}{ Heterogeneity } \\
\hline & & & & & $\overline{1^{2}(\%)}$ & $\mathrm{Ph}$ \\
\hline Overall & 9 & 3602 & $1.45(1.19-1.78)$ & $<0.001$ & 81 & $<0.001$ \\
\hline Study for subgroup analysis & 8 & 2775 & $1.63(1.27-2.07)$ & $<0.001$ & 62 & 0.01 \\
\hline \multicolumn{7}{|l|}{ Race } \\
\hline Caucasian & 4 & 1660 & $1.21(1.08-1.36)$ & 0.001 & 0 & 0.43 \\
\hline Asian & 4 & 1115 & $2.31(1.70-3.14)$ & $<0.001$ & 0 & 0.85 \\
\hline \multicolumn{7}{|l|}{ Sample size } \\
\hline$\geq 200$ & 4 & 567 & $1.57(1.09-2.26)$ & 0.02 & 69 & 0.02 \\
\hline$<200$ & 4 & 2208 & $1.85(1.17-2.92)$ & 0.008 & 60 & 0.06 \\
\hline \multicolumn{7}{|l|}{ Histology type } \\
\hline Clear cell carcinoma & 3 & 1450 & $1.75(1.27-2.43)$ & $<0.001$ & 0 & 0.46 \\
\hline Others & 5 & 1325 & $1.58(1.16-2.15)$ & 0.004 & 71 & 0.009 \\
\hline \multicolumn{7}{|l|}{ Mean age (years) } \\
\hline$\geq 65$ & 1 & 587 & - & - & - & - \\
\hline$<65$ & 7 & 2188 & $1.59(1.24-2.06)$ & $<0.001$ & 65 & 0.009 \\
\hline \multicolumn{7}{|l|}{ Treatment } \\
\hline Nephrectomy & 7 & 2590 & $1.56(1.22-2.00)$ & 0.001 & 61 & 0.02 \\
\hline Radiofrequency ablation & 1 & 185 & - & - & - & - \\
\hline \multicolumn{7}{|l|}{ Cut-off value of NLR } \\
\hline$\geq 2.75$ & 4 & 1806 & $1.61(1.10-2.35)$ & 0.01 & 73 & 0.01 \\
\hline$<2.75$ & 4 & 969 & $1.79(1.14-2.81)$ & 0.01 & 54 & 0.09 \\
\hline \multicolumn{7}{|l|}{$\begin{array}{l}\text { Mean time of follow-up } \\
\text { (months) }\end{array}$} \\
\hline$\geq 60$ & 3 & 491 & $1.65(1.07-2.55)$ & 0.02 & 59 & 0.09 \\
\hline$<60$ & 4 & 1697 & $1.66(1.07-2.56)$ & 0.02 & 73 & 0.01 \\
\hline
\end{tabular}

\section{Subgroup analyses based on histology type}

Considering that histology type may be the source of heterogeneity, we especially performed subgroup analyses based on histology types of RCC patients. The results revealed that histology types could change heterogeneity significantly. As shown in Table 3, pretreatment NLR could predict the outcome of clear cell RCC patients, including OS in nonmetastatic RCC $(\mathrm{HR}=1.75,95 \% \mathrm{CI}$ : $1.03-2.99, p=0.04 ; I^{2}=69 \%$ ), OS in metastatic RCC $\left(\mathrm{HR}=2.24,95 \% \mathrm{CI}: 1.55-3.25, p<0.001 ; I^{2}=0 \%\right)$, DFS in nonmetastatic RCC (HR $=1.75,95 \% \mathrm{CI}: 1.27-2.43, p<$ $\left.0.001 ; I^{2}=0 \%\right)$, PFS in metastatic RCC $(\mathrm{HR}=2.40,95 \% \mathrm{CI}$ : $\left.1.82-3.18, \mathrm{p}<0.001 ; I^{2}=0 \%\right)$, and CSS in nonmetastatic RCC $\left(\mathrm{HR}=2.77,95 \% \mathrm{CI}: 1.78-4.32, \mathrm{p}<0.001 ; I^{2}=0 \%\right)$.

\section{OS and PFS in patients treated with ICls}

In addition to the above analysis, we also investigated the prognostic role of NLR in metastatic RCC patients treated with immune checkpoint inhibitors (ICIs). The results indicated that the high level of NLR was significantly associated with worse OS $(\mathrm{HR}=3.92,95 \% \mathrm{CI}$ :
2.00-7.69, $\left.p<0.001 ; I^{2}=0 \%\right)$ and PFS (HR $=2.20,95 \%$ CI: $95 \%$ CI: 1.61-3.01, p $<0.001 ; I^{2}=20 \%$ ) (Fig. 4).

\section{Publication bias}

Publication bias was assessed, respectively for OS, DFS/PFS, and CSS without considering the stage of RCC patients. For both OS and DFS/PFS, the funnel plots were asymmetric (Fig. S1). Disappointingly, the Egger's test also showed some degree of publication bias (both $p<0.001$ ). Therefore, the trim and fill method was carried out to examine the funnel plot's asymmetry by using hypothetically non-published studies. The recalculated results indicated that elevated NLR was significantly associated with OS (HR: $1.51,95 \%$ CI: $1.28-$ $1.79, p<0.001$ ) and DFS/PFS (HR: 1.96, 95\%CI: $1.42-2.72$, $p<0.001$ ), indicating the stability of the results (Fig. S2). For CSS, the funnel plot was relatively symmetric (Fig. S1). Moreover, the Egger's test showed that there was no obvious publication bias $(p=0.285)$.

\section{Quality of evidence}

The assessment of the quality of evidence was performed for OS, DFS/PFS, and CSS which were critical in 
Table 3 Subgroup analyses based on histology type

\begin{tabular}{|c|c|c|c|c|c|c|}
\hline \multirow[t]{2}{*}{ Subgroup } & \multirow{2}{*}{$\begin{array}{l}\text { No. of } \\
\text { studies }\end{array}$} & \multirow{2}{*}{$\begin{array}{l}\text { No. of } \\
\text { patients }\end{array}$} & \multirow[t]{2}{*}{ HR $(95 \%$ Cl) } & \multirow[t]{2}{*}{$P$ value } & \multicolumn{2}{|c|}{ Heterogeneity } \\
\hline & & & & & $P^{2}(\%)$ & $\mathrm{Ph}$ \\
\hline \multicolumn{7}{|l|}{ OS in nonmetastatic RCC } \\
\hline Overall & 8 & 4113 & $1.78(1.24-2.56)$ & $<0.001$ & 85 & 0.002 \\
\hline Clear cell RCC & 4 & 2506 & $1.75(1.03-2.99)$ & 0.04 & 69 & 0.04 \\
\hline Others & 4 & 1607 & $2.15(1.61-2.87)$ & $<0.001$ & 6 & 0.36 \\
\hline \multicolumn{7}{|l|}{ OS in metastatic RCC } \\
\hline Overall & 11 & 1420 & $2.04(1.58-2.64)$ & $<0.001$ & 72 & $<0.001$ \\
\hline Clear cell carcinoma & 3 & 309 & $2.24(1.55-3.25)$ & $<0.001$ & 0 & 0.92 \\
\hline Others & 8 & 1111 & $1.99(1.47-2.68)$ & $<0.001$ & 77 & $<0.001$ \\
\hline \multicolumn{7}{|l|}{ DFS in nonmetastatic RCC } \\
\hline Overall & 8 & 3602 & $1.45(1.19-1.78)$ & $<0.001$ & 81 & $<0.001$ \\
\hline Clear cell carcinoma & 3 & 1450 & $1.75(1.27-2.43)$ & $<0.001$ & 0 & 0.46 \\
\hline Others & 5 & 1325 & $1.58(1.16-2.15)$ & 0.004 & 71 & 0.009 \\
\hline \multicolumn{7}{|l|}{ PFS in metastatic RCC } \\
\hline Overall & 9 & 891 & $2.99(2.82-3.18)$ & $<0.001$ & 18 & 0.28 \\
\hline Clear cell carcinoma & 4 & 382 & $2.40(1.82-3.18)$ & $<0.001$ & 0 & 0.64 \\
\hline Others & 5 & 509 & $3.02(2.84-3.22)$ & $<0.001$ & 28 & 0.24 \\
\hline \multicolumn{7}{|c|}{ CSS in nonmetastatic RCC } \\
\hline Overall & 4 & 2314 & $2.31(1.61-3.33)$ & $<0.001$ & 14 & 0.32 \\
\hline Clear cell carcinoma & 3 & 1679 & $2.77(1.78-4.32)$ & $<0.001$ & 0 & 0.47 \\
\hline Others & 1 & 635 & - & - & - & - \\
\hline
\end{tabular}

evaluating the prognosis of RCC patients. The results showed that the quality of evidence of OS and DFS/PFS was both "very low" because of observational studies, some degree of publication bias, and significant heterogeneity. However, the quality of evidence of CSS was "low" due to observational studies (Table S2).

\section{Discussion}

Prognostic markers have multiple applications in the diagnosis, treatment, and prediction of clinical outcome and can contribute to choosing the best treatment strategy. Pretreatment NLR, as a prognostic predictor for RCC, has been evaluated by numerous studies, but they
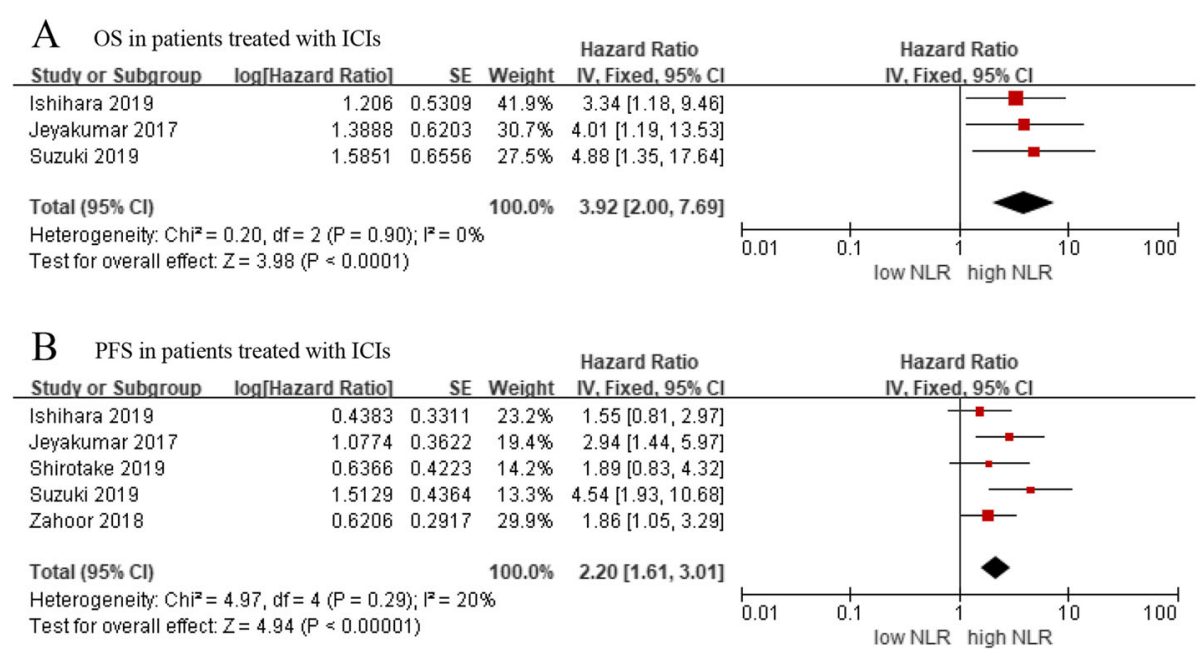

Fig. 4 a OS in RCC patients treated with ICls, b PFS in RCC patients treated with ICls 
reported controversial results. Thus, the aim of this systematic review and meta-analysis of 6461 RCC patients was to clarify the prognostic value of pretreatment NLR in RCC patients. The results indicated that elevated pretreatment NLR was significantly associated with poorer OS, DFS, and CSS in nonmetastatic RCC patients. Similarly, high pretreatment NLR also showed significant association with worse OS and PFS in metastatic RCC patients. To further explore the source of heterogeneity, we performed subgroup analyses according to the features of enrolled studies, which also demonstrated the stability and reliability of our results. Collectively, the pooled data from the present systematic review and meta-analysis demonstrated that NLR may serve as a prognostic indicator in RCC patients and would be helpful in guiding clinical decision-making and selecting individualized treatment strategies.

It is largely recognized that systemic inflammatory response and tumor microenvironment are essential in the development and progression of cancer [5, 41]. Some researchers have shown cancer-related inflammatory response consists of cytokines, chemokines, transcription factors, and inflammatory cells, which play decisive roles at different stages of tumor development including initiation, promotion, malignant conversion, invasion, and metastasis [42, 43]. Hence, several inflammatory biomarkers, such as platelet-to-lymphocyte ratio (PLR) [44], lymphocyte-to-monocyte ratio (LMR) [45], C-reavtive protein to albumin ratio (CAR) [46], C-reactive protein (CRP) [47] and modified Glasgow Prognostic Score (mGPS) [48] are the potential prognostic biomarkers in RCC patients.

Recently, various studies investigated the prognostic value of NLR in RCC patients and the function of neutrophils and lymphocytes may be responsible for the underlying mechanisms. Neutrophils are usually regarded as an important part in the acute phase of inflammation and confer resistance against microbes. Some studies showed that neutrophils were involved in cancer development. Neutrophils could directly affect tumor cells to promote cancer progression. Moreover, neutrophils may indirectly change the tumor microenvironment to promote cancer metastasis [49]. In addition, neutrophils could release tumor growth promoters or immunoregulatory mediators, including vascular endothelial growth factor (VEGF) to affect cancer progression, which is generally regarded as an important part in tumor angiogenesis and has been indicated by the inhibitory effects of anti-VEGF antibodies on tumor growth in vivo [50-52]. By contrast, lymphocytes reflect on cell-mediated immunity and are essential in anti-tumor immune responses. Increased infiltration of lymphocytes in the tumor region has been associated with better responsiveness to therapy and better prognosis in patients with solid tumors [53]. Moreover, lymphopenia, with a decrease in CD4 + T-cells, which are often observed in cancer patients, compromises the anti-tumor response mediated by lymphocytes [54]. In other words, NLR not only reflects the inflammatory response in patients, but it also represents the decline of anti-tumor immunity, thus bringing a new perspective in determining the outcome of RCC patients.

Several meta-analyses have discussed the relationship between NLR and prognosis in RCC patients [55, 56]. Their results were similar to our results, but these metaanalyses did not perform sensitivity analysis and subgroup analysis to evaluate the source of heterogeneity and assess the publication bias. Furthermore, the advent of ICIs has changed the management of metastatic RCC. In particular, we investigated OS and PFS in metastatic RCC patients treated with ICIs, and the negative association was also confirmed in these RCC patients. Additionally, in this analysis, we found that heterogeneity was significantly reduced by dividing the study population according to the race of patients, namely, Caucasian and Asian RCC patients. Besides, we also noted that heterogeneity was significantly reduced by limiting the histology type to clear cell RCC. Therefore, when we explore the clinical role of NLR, it would be better to understand the histology type of patients. Moreover, there were several different defined methods about NLR in our studies. Some studies regarded NLR as a continuous variable, whereas some studies divided it into two groups based on ROC curve, median value, $\mathrm{X}$ tile, and other methods. These different defined methods could potentially lead to heterogeneity. Of note, our study mainly evaluated the prognostic value of the pretreatment NLR. Several studies have shown that the post-treatment NLR was also an effective prognostic biomarker in RCC patients $[44,57,58]$. Therefore, the dynamic detection of the peripheral blood NLR level during treatment could play a more important prognostic role for RCC patients.

This study has several limitations that should be acknowledged. First, most of the included studies were retrospective and some of these studies had small sample sizes. Second, heterogeneity in some subgroup analyses was moderate or high. The possibility of selection biases or other unidentified confounders could not be completely avoided. Third, a certain degree of publication bias in our study may weaken the quality of evidence. Thus, the trim and fill method was performed and the adjusted results validated the stability of our results. Finally, there was no established cut-off value of NLR. Most scholars selected a cut-off value based on the highest sensitivity and specificity or used predefined cut-off values from other studies. Therefore, more largescale prospective studies are needed to establish the standard cut-off value of NLR and provide more evidence. 


\section{Conclusions}

Our meta-analysis demonstrated that elevated pretreatment NLR is an indicator associated with poor prognosis in RCC patients. As a potential prognostic biomarker, urologists could combine NLR with TNM stage, Fuhrman nuclear grade, histological subtype and other widely accepted prognostic indicators to more precisely predict the outcome of RCC patients.

\section{Supplementary information}

Supplementary information accompanies this paper at https://doi.org/10. 1186/s12894-020-00665-8.

Additional file 1: Figure S1. (a) Funnel plot of NLR and OS, (b) funnel plot of NLR and DFS/PFS, (c) funnel plot of NLR and CSS

Additional file 2: Figure S2. (a) Funnel plot adjusted with trim and fill method for OS, (b) for DFS/PFS.

Additional file 3: Table S1. Newcastle-Ottawa scale score of the reviewed studies

Additional file 4: Table S2. Evaluation of the quality of evidence according to GRADE system

\section{Abbreviations}

CAR: C-reactive protein to albumin ratio; Cl: Confidence intervals; CRP: Creactive protein; CSS: Cancer-specific survival; DFS: Disease-free survival: GRADE: Grading of Recommendations Assessment, Development, and Evaluation; HR: Hazard ratio; ICls: Immune checkpoint inhibitors; LMR: Lymphocyte-to-monocyte ratio; mGPS: Modified Glasgow Prognostic Score; NLR: Neutrophil-to-lymphocyte ratio; OS: Overall survival; PLR: Plateletto-lymphocyte ratio; PFS: Progression-free survival; RCC: Renal cell carcinoma; ROC curve: Receiver operating characteristic curve

\section{Acknowledgements}

We thank two reviewers for providing very useful and professional comments during the revision of this study.

\section{Authors' contributions}

YS, BW, and DW conceived and designed the research. YS, QC and WJ performed data acquisition, data analysis and statistical analysis. BW and ZZ assisted with data acquisition, data analysis and manuscript preparation. YS, BW, and DW contributed in writing the manuscript. All authors read and approved the final manuscript.

\section{Funding}

This study was supported by the National Natural Science Foundation of China (grant no. 81970662), Shanxi Key Research and Development project (grant no. 201803D31110), Shanxi "1331 project" Key Innovative Research Team, and Innovation Team Fund Program of First Hospital of Shanxi Medical University (TY1604). The role of funders was in the design and writing the study.

\section{Availability of data and materials}

All data generated or analysed during this study are included in this published article.

\section{Ethics approval and consent to participate}

Not applicable.

\section{Consent for publication}

Not applicable.

\section{Competing interests}

The authors declare that they have no competing interests.

\section{Author details}

${ }^{1}$ Shanxi Medical University, Taiyuan 030001, Shanxi, People's Republic of China. ${ }^{2}$ Department of Urology, First Hospital of Shanxi Medical University, Taiyuan 030001, Shanxi, People's Republic of China. ${ }^{3}$ National Cancer Center/National Clinical Research Center for Cancer/Cancer Hospital \& Shenzhen Hospital, Chinese Academy of Medical Sciences and Peking Union Medical College, Shenzhen 518116, People's Republic of China.

Received: 17 February 2020 Accepted: 30 June 2020

Published online: 06 July 2020

\section{References}

1. Siegel RL, Miller KD, Jemal A. Cancer statistics, 2019. CA Cancer J Clin. 2019; 69(1):7-34.

2. Capitanio U, Bensalah K, Bex A, Boorjian SA, Bray F, Coleman J, Gore JL, Sun M, Wood C, Russo P. Epidemiology of renal cell carcinoma. Eur Urol. 2019; 75(1):74-84.

3. Moch H, Cubilla A, Humphrey P, Reuter V, Ulbright T. The 2016 WHO classification of Tumours of the urinary system and male genital organs-part a: renal, penile, and testicular Tumours. Eur Urol. 2016;70(1):93-105.

4. Grivennikov SI, Greten FR, Karin M. Immunity, inflammation, and Cancer. Cell. 2010;140(6):883-99.

5. Khandia R, Munjal A. Interplay between inflammation and cancer. Adv Protein Chem Struct Biol. 2020;119:199-245.

6. McMillan DC. Systemic inflammation, nutritional status and survival in patients with cancer. Curr Opin Clin Nutr Metab Care. 2009:12(3):223-6.

7. Bagley SJ, Kothari S, Aggarwal C, Bauml JM, Alley EW, Evans TL, Kosteva JA, Ciunci CA, Gabriel PE, Thompson JC. Pretreatment neutrophil-to-lymphocyte ratio as a marker of outcomes in nivolumab-treated patients with advanced non-small-cell lung cancer. Lung Cancer. 2017;7(1):13-20.

8. Wu Y, Li C, Zhao J, Yang L, Liu F, Zheng H, Wang Z, Xu Y. Neutrophil-tolymphocyte and platelet-to-lymphocyte ratios predict chemotherapy outcomes and prognosis in patients with colorectal cancer and synchronous liver metastasis. World J Surg Oncol. 2016;14(1):289-93.

9. Cho HB, Hur HW, Kim SW, Kim SH, Kim JH, Kim YT, Lee K. Pretreatment neutrophil to lymphocyte ratio is elevated in epithelial ovarian cancer and predicts survival after treatment. Cancer Immunol Immunother. 2009;58(1):15-23.

10. Dalpiaz O, Luef T, Seles M, Stotz M, Stojakovic T, Rummer K, Zigeuner R, Hutterer GC, Pichler M. Critical evaluation of the potential prognostic value of the pretreatment-derived neutrophil-lymphocyte ratio under consideration of $\mathrm{C}$-reactive protein levels in clear cell renal cell carcinoma. Br J Cancer. 2017;116(1):85-90.

11. Shirotake S, Takamatsu K, Mizuno R, Kaneko GO, Nishimoto K, Oya M, Oyama M. Serum lactate dehydrogenase before Nivolumab treatment could be a therapeutic prognostic biomarker for patients with metastatic clear cell renal cell carcinoma. Anticancer Res. 2019;39(8):4371-7.

12. Nunno VD, Mollica V, Gatto L, Santoni M, Cosmai L, Porta C, Massari F. Prognostic impact of neutrophil-to-lymphocyte ratio in renal cell carcinoma: a systematic review and meta-analysis. Immunotherapy. 2019;11(7):631-43.

13. Stang A. Critical evaluation of the Newcastle-Ottawa scale for the assessment of the quality of nonrandomized studies in meta-analyses. Eur J Epidemiol. 2010;25(9):603-5.

14. Tierney JF, Stewart LA, Ghersi D, Burdett S, Sydes MR. Practical methods for incorporating summary time-to-event data into meta-analysis. Trials. 2007; 8(1):16.

15. Parmar MK, Torri V, Stewart L. Extracting summary statistics to perform meta-analyses of the published literature for survival endpoints. Stat Med. 1998:17(24):2815-34

16. Dersimonian R, Nan L. Meta-analysis in clinical trials. Control Clin Trials. 1986; 7(3):177-88.

17. Guyatt G, Oxman A, Akl E, Kunz R, Vist G, Brozek J, Norris S, Falck-Ytter Y, Glasziou P, DeBeer H, et al. GRADE guidelines: 1. Introduction-GRADE evidence profiles and summary of findings tables. J Clin Epidemiol. 2011; 64(4):383-94.

18. Chen Z, Wang K, Lu H, Xue D, Fan M, Zhuang Q, Yin S, He X, Xu R. Systemic inflammation response index predicts prognosis in patients with clear cell renal cell carcinoma: a propensity score-matched analysis. Cancer Manag Res. 2019;11:909-19.

19. Huszno J, Kolosza Z Mrochem-Kwarciak J, Rutkowski T, Skladowski K The role of neutrophil-lymphocyte ratio, platelet-lymphocyte ratio, 
and platelets in the prognosis of metastatic renal cell carcinoma. Oncology. 2019;97(1):7-17.

20. Ishihara H, Tachibana H, Takagi T, Kondo T, Fukuda H, Yoshida K, lizuka J, Kobayashi $\mathrm{H}$, Okumi M, Ishida $\mathrm{H}$, et al. Predictive impact of peripheral blood markers and C-reactive protein in Nivolumab therapy for metastatic renal cell carcinoma. Target Oncol. 2019;14(4):453-63.

21. Silagy A, Flynn J, Mano R, Blum K, Marcon J, DiNatale R, Sanchez A, Carlo M, Motzer R, Coleman J, et al. Clinicopathologic features associated with survival after cytoreductive nephrectomy for nonclear cell renal cell carcinoma. Urol Oncol. 2019;37(11):9-16.

22. Suzuki K, Terakawa T, Furukawa J, Harada K, Hinata N, Nakano Y, Fujisawa M. C-reactive protein and the neutrophil-to-lymphocyte ratio are prognostic biomarkers in metastatic renal cell carcinoma patients treated with nivolumab. Int J Clin Oncol. 2019;25(1):135-44.

23. Takagi $T$, Fukuda $H$, Kondo $T$, Ishihara $H$, Yoshida K, Kobayashi $H$, lizuka J, Okumi M, Ishida H, Tanabe K. Prognostic markers for refined stratification of IMDC intermediate-risk metastatic clear cell renal cell carcinoma treated with first-line tyrosine kinase inhibitor therapy. Target Oncol. 2019;14(2):179-86.

24. Tu X, Wang F, Chang T, Zhang C, Zhang M, Liu Z, Qiu S, Yang L, Wei Q. Predictive value of preoperative neutrophil-to-lymphocyte ratio in nonmetastatic papillary renal cell carcinoma patients after receiving curative surgery. Cancer Manag Res. 2019;11:7515-24.

25. Widz D, Mitura P, Buraczynski P, Plaza P, Bar M, Cabanek M, Nowak G, Ostrowska A, Bar K. Preoperative neutrophil-lymphocyte ratio as a predictor of overall survival in patients with localized renal cell carcinoma. Urol J. 2020;17(1):30-5.

26. Zheng Y, Bao LM, Ye J, Pan Y, Wang Q, Gao X. Impact of diabetes mellitus on the prognostic value of the neutrophil-lymphocyte ratio in renal cell carcinoma. Exp Ther Med. 2019;17(2):1268-75.

27. Kim SH, Kwon WA, Kim S, Joung JY, Seo HK, Lee KH, Chung J. The neutrophil-to-lymphocyte ratio makes the Heng risk model improve better the prediction of overall survival in metastatic renal cell cancer patients. Jpn J Clin Oncol. 2018:48(9):835-40.

28. Zahoor H, Barata PC, Jia X, Martin A, Allman KD, Wood LS, Gilligan TD, Grivas P, Ornstein MC, Garcia JA, et al. Patterns, predictors and subsequent outcomes of disease progression in metastatic renal cell carcinoma patients treated with nivolumab. J Immunother Cancer. 2018;6(1):107.

29. Zheng Y, Bao L, Wang W, Wang Q, Pan Y, Gao X. Prognostic impact of the controlling nutritional status score following curative nephrectomy for patients with renal cell carcinoma. Medicine. 2018;97(49):e13409.

30. Chang X, Zhang F, Liu T, Wang W, Guo H. Neutrophil-to-lymphocyte ratio as an independent predictor for survival in patients with localized clear cell renal cell carcinoma after radiofrequency ablation: a propensity score matching analysis. Int Urol Nephrol. 2017:49(6):967-74.

31. Jeyakumar G, Kim S, Bumma N, Landry C, Silski C, Suisham S, Dickow B, Heath E, Fontana J, Vaishampayan U. Neutrophil lymphocyte ratio and duration of prior anti-angiogenic therapy as biomarkers in metastatic RCC receiving immune checkpoint inhibitor therapy. J Immunother Cancer. 2017; 5(1):82.

32. Grivas N, Kafarakis V, Tsimaris I, Raptis P, Hastazeris K, Stavropoulos NE. Clinico-pathological prognostic factors of renal cell carcinoma: a 15-year review from a single center in Greece. Urol Ann. 2014;6(2):116-21.

33. Viers BR, Houston Thompson R, Boorjian SA, Lohse CM, Leibovich BC, Tollefson MK. Preoperative neutrophil-lymphocyte ratio predicts death among patients with localized clear cell renal carcinoma undergoing nephrectomy. Urol Oncol. 2014;32(8):1277-84.

34. Cetin B, Berk V, Kaplan MA, Afsar B, Tufan G, Ozkan M, Isikdogan A, Benekli $\mathrm{M}$, Coskun U, Buyukberber $\mathrm{S}$. Is the pretreatment neutrophil to lymphocyte ratio an important prognostic parameter in patients with metastatic renal cell carcinoma? Clin Genitour cancer. 2013;11(2):141-8.

35. de Martino M, Pantuck AJ, Hofbauer S, Waldert M, Shariat SF, Belldegrun AS, Klatte T. Prognostic impact of preoperative neutrophilto-lymphocyte ratio in localized nonclear cell renal cell carcinoma. J Urol. 2013;190(6):1999-2004.

36. Fox P, Hudson M, Brown C, Lord S, Gebski V, De Souza P, Lee CK. Markers of systemic inflammation predict survival in patients with advanced renal cell cancer. Br J Cancer. 2013:109(1):147-53.

37. Keizman D, Gottfried M, Ish-Shalom M, Maimon N, Peer A, Neumann A, Hammers $\mathrm{H}$, Eisenberger MA, Sinibaldi V, Pili R, et al. Active smoking may negatively affect response rate, progression-free survival, and overall survival of patients with metastatic renal cell carcinoma treated with sunitinib. Oncologist. 2014;19(1):51-60

38. Pichler M, Hutterer GC, Stoeckigt C, Chromecki TF, Stojakovic T, Golbeck S, Eberhard K, Gerger A, Mannweiler S, Pummer K, et al. Validation of the pre-treatment neutrophil-lymphocyte ratio as a prognostic factor in a large European cohort of renal cell carcinoma patients. Br J Cancer. 2013;108(4):901-7.

39. Santoni M, De Giorgi U, lacovelli R, Conti A, Burattini L, Rossi L, Luca Burgio S, Berardi R, Muzzonigro G, Cortesi E, et al. Pre-treatment neutrophil-tolymphocyte ratio may be associated with the outcome in patients treated with everolimus for metastatic renal cell carcinoma. Br J Cancer. 2013;109(7): $1755-9$

40. Ohno Y, Nakashima J, Ohori M, Hatano T, Tachibana M. Pretreatment neutrophil-to-lymphocyte ratio as an independent predictor of recurrence in patients with nonmetastatic renal cell carcinoma. J Urol. 2010;184(3):873-8.

41. Hanahan D, Weinberg RA. Hallmarks of cancer: the next generation. Cell. 2011;144(5):646-74.

42. Diakos Cl, Charles KA, McMillan DC, Clarke S. Cancer-related inflammation and treatment effectiveness. Lancet Oncol. 2014;15(11):e493-503.

43. Balkwill F, Mantovani A. Inflammation and cancer: back to Virchow? Lancet Oncol. 2001;357(9255):539-45.

44. Kim TW, Lee JH, Shim KH, Choo SH, Choi JB, Ahn HS, Kim SJ, Kim SI. Prognostic significance of preoperative and follow-up neutrophil-tolymphocyte ratio and platelet-to-lymphocyte ratio in patients with nonmetastatic clear cell renal cell carcinoma. Invest Clin Urol. 2019;60(1):14-20.

45. Yamamoto Y, Matsuyama H, Matsumoto H, Sakano S, Fuji N, Oba K, Yamamoto M, Kamiryo Y, Hiragino T, Nagao K, et al. Prognostic value of risk stratification using blood parameters for nivolumab in Japanese patients with metastatic renal-cell carcinoma. Jpn J Clin Oncol. 2020; 50(2):214-20.

46. Zhou W, Zhang GL. C-reactive protein to albumin ratio predicts the outcome in renal cell carcinoma: a meta-analysis. PLoS One. 2019;14(10): e0224266.

47. Tsujino T, Komura K, Hashimoto T, Muraoka R, Satake N, Matsunaga T, Tsutsumi T, Yoshikawa Y, Takai T, Minami K, et al. C-reactive protein-albumin ratio as a prognostic factor in renal cell carcinoma - a data from multiinstitutional study in Japan. Urol Oncol. 2019;37(11):e811-8.

48. Ohmura H, Uchino K, Kajitani T, Sakamoto N, Baba E. Predictive value of the modified Glasgow prognostic score for the therapeutic effects of moleculartargeted drugs on advanced renal cell carcinoma. Mol Clin Oncol. 2017;6(5): 669-75.

49. Shaul M, Fridlender Z. Tumour-associated neutrophils in patients with cancer. Nat Rev Clin Oncol. 2019:16(10):601-20.

50. Templeton AJ, McNamara MG, Šeruga B, Vera-Badillo FE, Aneja P, Ocaña A, Leibowitz-Amit R, Sonpavde G, Knox JJ, Tran B, et al. Prognostic role of neutrophil-to-lymphocyte ratio in solid tumors: a systematic review and meta-analysis. J Natl Cancer Inst. 2014;106(6):2.

51. Masucci MT, Minopoli M, Carriero MV. Tumor Associated Neutrophils. Their Role in Tumorigenesis, Metastasis, Prognosis and Therapy. Front Oncol. 2019;9:1146.

52. Kusumanto YH, Dam WA, Hospers GAP, Meijer C, Mulder NH. Platelets and granulocytes, in particular the neutrophils, form important compartments for circulating vascular endothelial growth factor. Angiogenesis. 2003;6(4):283-7.

53. Gooden MJM, de Bock GH, Leffers N, Daemen T, Nijman HW. The prognostic influence of tumour-infiltrating lymphocytes in cancer: a systematic review with meta-analysis. Br J Cancer. 2011;105(1):93-103.

54. Wang BH, Gu WJ, Wan FN, Shi GH, Ye DW. Prognostic significance of the dynamic changes of systemic inflammatory response in metastatic renal cell carcinoma. Int Braz J Urol. 2019:45(1):89-99.

55. Boissier R, Campagna J, Branger N, Karsenty G, Lechevallier E. The prognostic value of the neutrophil-lymphocyte ratio in renal oncology: a review. Urol Oncol. 2017:35(4):135-41.

56. Jiang T, Qiao M, Zhao C, Li XF, Gao GH, Su CX, Ren SX, Zhou CC. Pretreatment neutrophil-to-lymphocyte ratio is associated with outcome of advanced-stage cancer patients treated with immunotherapy: a metaanalysis. Cancer Immunol Immunother. 2018;67(5):713-27.

57. Ohno Y, Nakashima J, Ohori M, Gondo T, Hatano T, Tachibana M. Followup of neutrophil-to-lymphocyte ratio and recurrence of clear cell renal cell carcinoma. J Urol. 2012;187(2):411-7. 
58. Ito K, Masunaga A, Tanaka N, Mizuno R, Shirotake S, Yasumizu Y, Ito Y, Miyazaki Y, Hagiwara M, Kanao K, et al. Impact of inflammatory marker levels one month after the first-line targeted therapy initiation on progression-free survival prediction in patients with metastatic clear cell renal cell carcinoma. Jpn J Clin Oncol. 2019;49(1):69-76.

\section{Publisher's Note}

Springer Nature remains neutral with regard to jurisdictional claims in published maps and institutional affiliations.

Ready to submit your research? Choose BMC and benefit from:

- fast, convenient online submission

- thorough peer review by experienced researchers in your field

- rapid publication on acceptance

- support for research data, including large and complex data types

- gold Open Access which fosters wider collaboration and increased citations

- maximum visibility for your research: over $100 \mathrm{M}$ website views per year

At $\mathrm{BMC}$, research is always in progress.

Learn more biomedcentral.com/submissions 